\title{
The Recruitment of Passion and Community in the Service of Capital: Community Managers in the Digital Games Industry
}

\section{Aphra Kerr \& John D. Kelleher}

To cite this article: Aphra Kerr \& John D. Kelleher (2015) The Recruitment of Passion and Community in the Service of Capital: Community Managers in the Digital Games Industry, Critical Studies in Media Communication, 32:3, 177-192, DOI: 10.1080/15295036.2015.1045005

To link to this article: https://doi.org/10.1080/15295036.2015.1045005

曲 Published online: 26 Jun 2015.

Submit your article to this journal $\widetilde{ }$

Џ Article views: 577

Q View related articles 2

View Crossmark data $\nearrow$

Citing articles: 3 View citing articles $\widetilde{ }$ 


\title{
The Recruitment of Passion and Community in the Service of Capital: Community Managers in the Digital Games Industry
}

\author{
Aphra Kerr \& John D. Kelleher
}

Globalization and technical change have had a significant impact on work in the cultural industries. Online games are services that are networked, operate around the clock and require ongoing player and company input. The industry's content production networks are dispersed internationally, and many of its services are offered transnationally. These new services have generated new forms of work, like community management, which are often outsourced to near-to-market locations. Much of the research on media work is focused on high status creative occupations or the free labour of amateurs. This paper draws upon the findings of a content analysis of job advertisements and face-to-face interviews with community managers to examine the recruitment and work of community managers. Using scholarship on media production, media work and emotional labour this article argues that recruitment and organizational practices surrounding community managers appropriate passion, community, and experience in the service of capital, but also marginalize these workers. While community managers see themselves as creative workers, their visibility and creative autonomy are limited by organizational and workplace cultures.

Keywords: Games; Community Management; Work; Digital Labour; Gender

This paper aims to contribute to our understanding of digital media work through an examination of waged community managers in the digital games industry. This form of work takes place almost entirely online and these workers must "take care" of the user community and provide a communication channel between developers and

Aphra Kerr is a senior lecturer. Correspondence to: Aphra Kerr, Department of Sociology, Maynooth University, Auxilia Building, Maynooth, Kildare, Ireland; Email: aphra.kerr@nuim.ie; John Kelleher is a lecturer. Correspondence to: John D. Kelleher, School of Computing, Dublin Institute of Technology, Dublin, Ireland; Email: john.d.kelleher@dit.ie 


\section{A. Kerr and J. D. Kelleher}

players. This work is material in the sense that it uses computers, networks, and electricity, and is dependent on tools and technologies. It is also immaterial in the sense that it takes place online and demands the harnessing of affect and the performance of particular forms of subjectivity, often ones that mask existing gender and racial identities. In this article we argue that community managers both see themselves, and can be shown to be, creative symbol creators, even if their visibility and degree of creative autonomy is limited by pre-existing organizational, technical, and gender hierarchies.

The development of community manager roles needs to be situated within the broader context of increasingly transnational production networks and a shift in production models in the cultural industries from publishing individual commodities to creating cultural services. Media and game companies now employ workers to provoke, cajole, nurture, and invite users to have fun and play in gated "online communities." When share value depends on market share, unique users, and clicks, companies are turning to a range of techniques to "engage," retain, and convert user activity into revenue. One method for tracking users is data analytics, the second is the employment of community managers.

We know relatively little about community managers. They are relatively invisible and low status compared to the developers, artists, and programers who create the products they support, and the high profile celebrities brought in to do voiceovers and soundtracks. They are devoid of the advantages and privileges that "author" or "creative" might bring in unionized media industries (Caldwell, 2008, p. 58). Indeed, creative/technical distinctions are problematic when we examine the games industry, where programers tend to be paid the highest salaries and there is little unionization across all categories of occupation. Many community management jobs are offshored and often outsourced via agencies. These roles are absent from games industry reports, lobbying documents, industry websites, and conferences. Further, initial investigations seem to indicate that community management is one area of the games industry where there is a greater representation of women.

\section{Media Production and Digital Work}

The development of community manager roles needs to be situated within the broader context of globalization, capitalism, and the shift in cultural production logics from publishing and press models to new types of flow and service models (Bolin, 2011; Miège, 2011). Miège (1989, p. 12) identified three dominant "logics" of production across the cultural industries: a publishing logic, a written press logic, and a flow logic. The first is epitomized by the book publishing industry where traditionally consumers purchased one copy for personal use and the artist was compensated through a royalty and reproduction system. The written press logic covers the rapid production of a highly ephemeral product like daily newspapers with the employment of an industrial workforce. The flow logic is based on the traditional audio-visual media, like radio and television, and some forms of new media, where a single copy is diffused and received by a mass audience. In the flow model the 
challenge is to construct a continuous flow of programing and maintain audience loyalty. Flow media must manage a mixture of sources of finance including subscriptions, advertising, and in some cases license fees. Hesmondhalgh and Baker (2011) employed these logics in their study of work in the television, music, and magazine industries in the UK, even as they acknowledge that the logics might need updating.

Lacroix and Tremblay (1997) argue for a new "club logic," which recognises the importance of networked communication technologies and the increasingly important role of the distributor in media production. While a focus on the "central function" of distribution is useful, the club logic appears to be defined too broadly for our use and does not pay enough attention to the role of users. The spread of network technologies, new occupations like community managers, new self-funding models, and more data driven cultural production, challenge us to rethink the characteristics of existing cultural production logics. We need to explore how non-market or semi-market productions have a relational influence on the larger games field and an indirect impact on value. Certainly, what Miège (1989, p. 30) calls the large pool of "reserve workers," many of whom are unpaid but who are creating and sharing their work, nonetheless have an influence on contemporary media production. The game-players create some of the value in online games either directly, or indirectly, and as games have added online modes of play, maintaining the "atmosphere" of the game is a key goal if the game is to survive in the marketplace.

Bolin (2011) identifies how service based business models from the telecommunications sector are now more prevalent in the media industries. In telecommunications, companies provide the platform and infrastructure (e.g. network lines) while users provide the content. Thus the spread of the internet, trade, and network liberalization, and the application of computing and network power to data gathering and analysis have enabled new relationships between producers and consumers to develop. We consider the concept of the "business model" to be more limited than the concept of a production logic, and in what follows we begin to trace how new creative professions like community management and new roles for users might signal alterations to existing production logics, and perhaps a new production logic.

In the early 2000s, the publishing logic was dominant in the games industry and most independent or third party companies aimed to secure a publishing deal and produce a final product on compact disk. This logic still exists, but the emergence of subscription based massively multiplayer online games (MMOGs) and more recently free-to-play online games are an increasingly important part of the games industry. While subscription based MMOGs might correspond to the flow logic, a new service logic where game players create accounts and "play for free" but purchase a variety of assets to progress in the game, appears to constitute a new form of platform logic. Key to understanding these developments is the continuous engagement and interaction of the games company and game players, and the shift from shipping one finished product, to the provision of a series of updates, expansion packs, and opportunities to engage. There is an ongoing need to support, regulate, and engage the player base through a range of artefacts and it is within these industrial and 


\section{A. Kerr and J. D. Kelleher}

organizational changes that we must place community managers. They are part of a complex assemblage of human and non-human elements that attempt to govern game playing communities (Kerr, De Paoli, \& Keatinge, 2014), and maintain the flow of capital.

Media scholars have noted that production logics condition relationships of production and working conditions. The "Dynamics of Virtual Work" research network notes that ICTs have enabled the creation of entirely "new types of digital or virtual labour, both paid and unpaid, shifting the borderline between play and work and creating new types of unpaid labour connected with consumption and cocreation of services" (Huws, 2012). Some forms of waged digital labour are devoid of worker protections and akin to "less visible, unsung forms of traditional women's labour such as child care, housework, and surrogacy" (Scholz, 2013, p. 2). We consider "media work" to be a subset of broader types of digital work and a form of work that can be both precarious, as many other forms of digital labour are, and directly concerned with "symbol creation" as many other forms are not (Hesmondhalgh \& Baker, 2008, 2011). Games work is one sub-sector of the wider media industries.

Recent studies on digital media workers highlight their increasing precarity and the particular challenges faced by women, people of color, and people from lower socio-economic backgrounds both entering and staying in the industry (Banks, 2007; Gill \& Pratt, 2008; McRobbie, 2010). While flexibility can be desirable for some workers, its widespread deployment in the media industries has served to create fragmented portfolio careers, maintain a reserve army of workers, and individualize risk (Neff, 2012). We see a range of practices that operate explicitly, or implicitly, to exclude women, or people with caring responsibilities, from certain roles, i.e. working hours, informalization, and workplace culture (O'Brien, 2014). We also see that language is deployed to create hierarchies in ostensibly non-hierarchical organizations and in the creation of occupational roles that become known as "women's work" or "non-technical work." Many of these roles are in customer relations and these "customer facing" roles, even if mediated by technology, are often where more women are employed, and are where "soft" skills of verbal and written communication, management of emotions, diplomacy, and empathy are valued and exploited. The concept of "emotional labour" (Hochschild, 1983) has been deployed to understand the requirement to induce or suppress one's own emotions in order to project a particular countenance in some digital media roles (Hesmondhalgh \& Baker, 2008). Some of these roles have become feminized, even if they are performed by both men and women (Banks, 2009).

While attention has been paid to some new forms of digital labour, such as "crowdsourcing" (Caraway, 2011), little is known about community management in games or on social media more generally. What exists focuses mainly on the gameworld and game players, rather than the waged workers behind the screens (Bakioglu, 2013; Humphreys, 2008; Whitson, 2010). Further, there is relatively little on working conditions in the digital games industry (Consalvo, 2011; Deuze, Bowen, \& Allen, 2007; Dyer-Witheford \& De Peuter, 2009; Kerr, 2011). Current work 
suggests that the games industry faces a number of issues with regard to recruitment, retention, and workplace culture. The results of a 2014 games industry salary survey highlighted "long work hours, job instability, shifting business models, the fact that good games are hard to make, and cultural issues such as sexism" (Gamasutra, 2014, p. 1). In this survey $(n=2,111)$ the percentage of men employed across the occupational roles identified as: programers and engineers, artists and animators, game designers, producers, audio professionals, quality assurance testers, and business management never fell below 78\%. While this self-selected population is dominated by workers in the US and Canada (three-quarters of responses), it points to a persistent gendered structure of employment. Community managers and retail did not feature as occupational categories in the survey. In a smaller UK based online salary survey $(\mathrm{n}=850)$ community managers were included in the public relations category and median annual salaries were put at $£ 24,250$ (Dring, 2015). This article noted that there was a wide variance in community manager salaries and only junior designers and writers, and sales assistants, were paid less in the $\mathrm{UK}^{1}$

Community managers are also often excluded from policy discussions about the games industry. None of the recent reports on the games industry by agencies like Creative Skillset and NESTA, in the UK, mention community managers (Livingstone \& Hope, 2011; Skillset, 2010). Nevertheless, a search for community managers on online industry websites like Gamasutra and Gamesindustry.biz turns up thousands of articles on community managers. We might argue that the shift to games as a service is relatively recent and thus surveys by professional agencies, industry bodies and researchers have yet to adjust to this new division of labour. An alternative explanation is that community management does not have the status of core technical or design roles and therefore is excluded from definitions of "creative work" in both policy reports and industry surveys.

\section{Research Methods}

Studying workers in the games industry is a challenge. There are no independent statistics on the industry internationally, and current national industry and occupational data conflate the industry with the software, animation, and digital media industries. The games industry does produce statistics, but with little information on methodology, this data has to be treated carefully.

This project went through ethical approval in Maynooth University in 2013. Recruiting community mangers for interviews through human resource managers in multinational game companies proved difficult and subsequently we established that some worker contracts discouraged workers from talking about their jobs. To date we have conducted 15 hour-long face-to-face interviews with workers in the games industry in Ireland, of which five are with community managers in multinational games companies. To supplement our interviews we conducted a content analysis of 75 job advertisements for community managers in games companies. The interviews were used to inform the development of a coding frame for our content analysis and to provide context for the findings. 


\section{A. Kerr and J. D. Kelleher}

There is no central source for community management jobs so we relied on games industry and company websites. While our sample is biased towards jobs in large multinational companies, and positions advertised in English, these positions are located in multiple locations across North America, Europe, and Asia. The advertisements were imported into eHost, an open source annotation tool (https://code.google. $\mathrm{com} / \mathrm{p} / \mathrm{ehost} /$ ). We developed a coding frame based on our literature review and face-toface interviews, and we manually coded and annotated the files using these categories. These categories included channels (tools and technologies used in the job), type of contract, education, experience, game type, location, salary, skills, and other.

We employed techniques from natural language processing to analyze our corpus of annotated advertisements. One of the research questions of this project was to establish the key skills requirements of community managers. We used a word frequency approach to answer this question. The intuition underpinning this approach was that key skills would be mentioned frequently in the job specifications and therefore examining relatively frequently occurring words in the job specifications would provide insight into the key skill requirements. We used tag clouds to visualize these word frequencies. In a tag cloud word frequency is encoded using font size; i.e. the more frequent a word is the larger the word appears in the tag cloud.

When using word frequencies as the basis for a corpus analysis it is standard practice to normalize the text prior to calculating the word frequencies. Text normalization typically involves the removal of punctuation, the reduction of morphological variation, and the standardizing of word case. For example, following text normalization the following terms should all appear as instances of the same word: "Game," “games," "GAMES," “game?," "games!," and "game”. The removal of frequently occurring structural words - such as, determiners (the, a) and prepositions (at, on, in) -is also standard operation in the pre-processing of texts prior to the calculation of word frequencies. We used the Natural Language Toolkit (NLTK) (Bird, 2006) to normalize the text and remove structural words. Specifically, we converted all the text to lowercase, removed all punctuation, applied a stemmer to text to remove morphological variation, and excluded the structural words by removing all the words that appeared in the NLTK stop-word list. Once the text had been normalized we generated four tag clouds based on different subsets of the corpus. In the following section we contextualize this work, present the tag clouds and discuss our interpretation of the patterns that emerged in relation to our interviews.

\section{Community Managers, Transnational Work and Mobility}

The origins of this paper lie in a survey of the Irish games industry conducted in 2009 (Kerr \& Cawley, 2012). Of the 1,470 workers identified in 2009, 900 were employed in "other" occupations. When we delved further we identified a new category of occupation-the community manager-that had not been present in previous surveys. What was striking about these results was that most of the employment in the Irish games industry was not in programing, art, or design, but rather in community support, management, quality assurance, and localization. 
These people were not making games but were supporting online game playing communities across international markets.

The demographic profile of our games industry workers largely aligned with profiles of other digital media sectors, except in two respects. First, women are under-represented across the games industry in general (43\% of companies employ no women) and in content development functions, in particular. Women constituted only $13 \%$ of the total numbers employed, and when we removed those involved in online community support they constituted less than $7 \%$. Thus online community support employed more women than other occupational areas.

Second, we found that the industry employed a wide range of nationalities. By nationality, the largest number of employees were German $(n=333)$, followed by Irish $(n=297)$ and other European $(n=248)$, i.e. not French, German, Spanish, or Italian. The fourth largest nationality group was British $(n=233)$. Other nationalities included French $(n=174)$, Spanish $(n=72)$, and Italian $(n=64)$. Many people had relocated to work in the games industry in Ireland and the industry was able to take advantage of labour mobility in Europe to access the multilingual skills necessary for community support and localization jobs. Further analysis revealed that over $90 \%$ of employees were aged 35 years or younger.

When we broaden the analysis to our sample of international community manager advertisements we found that these roles are not being offshored to low cost locations. These roles are located in strategic locations that are proximate to large games companies, core language markets, and a highly mobile workforce. In some of these locations there is also a favorable tax or financial regime. In our sample positions were offered in: Dublin and Galway (Ireland), Hamburg and Berlin (Germany), Santa Monica, Redwood, San Francisco, El Segundo, Irvine and Austin (USA), Sao Paolo (Brazil), Helsinki (Finland), Versailles (France), Bucharest (Romania), Moscow (Russia), London (UK), Edmonton (Canada), Seoul (South Korea), Taipei (Taiwan), and Madrid (Spain).

The patterns that are emerging point to highly regionalized game markets, structured by geo-linguistic boundaries. English is the lingua franca of the industry, and in many multinational companies the only language workers have in common. Companies like Activision-Blizzard advertise positions in North America, Europe, and Asia, while Riot, a younger company, is mostly advertising in North and South America, and Europe. Interviews confirmed that community managers often moved country to work with a particular company and on a particular game, regardless of where the company was located.

Companies also recruited native language speakers of their target player base since that meant community managers could type more quickly and understand cultural nuances. A community manager could be responsible for the English language market in Europe and North America, or the global Polish speaking player community. Teams in Dublin employed native speakers of French, Italian, Spanish, German, Polish, Russian, Czech, and Turkish. The positions in Romania were looking for English, Czech, Italian, Spanish, German, Polish, and Romanian. In the USA you needed English, Latin American Spanish, Brazilian Portuguese, and 


\section{A. Kerr and J. D. Kelleher}

Japanese. In Korea, English and Korean. In many of the job descriptions and in the interviews it was clear that people were not only doing community support in different languages, they were also doing translation work.

\section{Recruitment and Community Managers}

The role of "game master" has existed informally for years in both digital and nondigital games and the role of "community manager" is a development of that. Initially unwaged game players performed these roles and in many online games volunteer players still play an important role in community management. Interviewees told us that staff might be hired as game masters and then later became more specialized in community management, quality assurance, or localization. With the spread of social networking, the internet and the professionalization of game development in the last decade, the role has expanded to include managing both in game, and third party social media spaces. In smaller companies the responsibility is spread across all workers. As a games company grows there is increased specialization and the role of community manager takes on more formality, although it appears from our research that the role is highly variable.

In our sample the companies who were advertising for community managers included many companies in the top ten by revenue in 2014 including ActivisionBlizzard, Riot, Electronic Arts, BioWare, Zenimax, Square Enix, and Sony, and Asian companies moving into North American and European markets like Webzen. One of our first findings related to missing information in the job advertisements. Only one of our 75 advertisements included information on remuneration, and only four gave any detail on benefits. Three of the job advertisements mentioned that the positions entailed working weekends, evenings, and holidays. Indeed, arranging interviews with community managers gave us some insight into the contingency of their hours as server, service, and product upgrades meant the rescheduling of interviews. One interviewee stated that from September until Christmas he did not expect to be home much. In a previous job he was given a laptop and cell phone and was on call 24 hours a day, seven days a week.

When we analyze the entire corpus of advertisements a clear feature is the frequency with which they deploy the term "community." Across all the advertisements we found that "community" was used 800 times, much more than the next five most frequent terms "social” (263), "player" (252), "games” (243), "team (213), and "experience" (203). The term brings with it a range of positive connotations and reinforces academic research that argues that online spaces in general, and online games in particular, can provide spaces in which to build forms of social capital (Steinkuehler \& Williams, 2006) and "virtual togetherness" (Bakardjieva, 2003). The use of "social" is also highly relevant and this term is deployed both in relation to "social media" and "sociability." Both "online communities" and "social media" point to the commodification of social relationships and the appropriation of the positive values usually associated with these terms. These also connect to the term "team." So sociability is deployed both through digital forms of communication as well as in face 


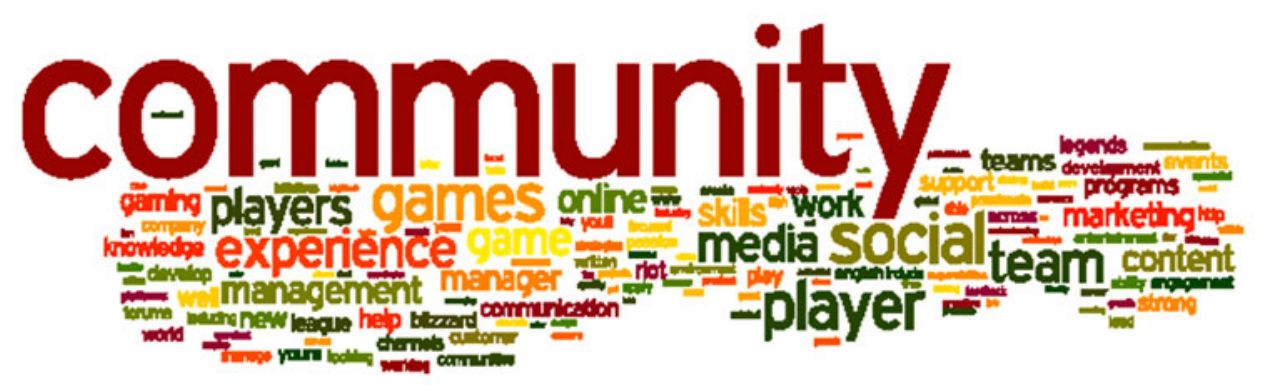

Figure 1 Tag Cloud Based on Frequency of Words across All Advertisements

to face situations with fellow employees, and intermittently at conventions with players. When allied to the frequent use of gamer and player we see a discursive erosion of boundaries between players and community managers.

Only $14 \%$ of our advertisements required a degree, while the rest did not mention an educational qualification. Of more importance than formal qualifications was experience, both informal gameplay experience and formal paid experience. One advertisement offered \$60,000-80,000 Canadian for three-five years' experience. This compares favorably to industry surveys and our interviewees. Some interviewees declined to give their salary, or said it was confidential, but others stated that an entry level community manager could expect to be paid about $€ 20,000-25,000$ and someone with five years' experience might earn $€ 27,000-38,000$. To put this in context, this is considerably lower than the average paid to a quality assurance tester ( $\$ 54,833 / € 48,928$ approximately) in the US games industry, according to the 2014 Gamasutra survey. Additional benefits included health insurance, a cell phone and free games. The relatively low level of pay in Ireland and the focus on experience, rather than qualifications, are two things that stand out from the analysis of job advertisements and from the interviews.

When we analyzed our corpus for skills the most frequently used terms were "passion" (66), "gaming knowledge" (50), "communication skills" (34) and "English" (32). When we looked at other skills in more detail again one term stood out- "passion" and variations of it. This term occurs with much greater frequency than communication skills or indeed language skills. Interviewees also talked about fostering the passion of game players and working in the games industry because they were passionate about games. We can see this term as a neoliberal call for (complete) and uncritical emotional commitment to an employer (Consalvo, 2011; Couldry \& Littler, 2011).

Passion was most frequently co-located with gaming knowledge and arguably, what many of these advertisements were doing was hailing fans and game players. This also, we suggest, excludes those who do not see themselves as passionate game players and blurs the boundaries between work and play. What becomes clear, therefore, is that experience in community management in informal or formal settings, and domain knowledge of games generally, or of particular games more specifically, is prioritized in these job advertisements. 


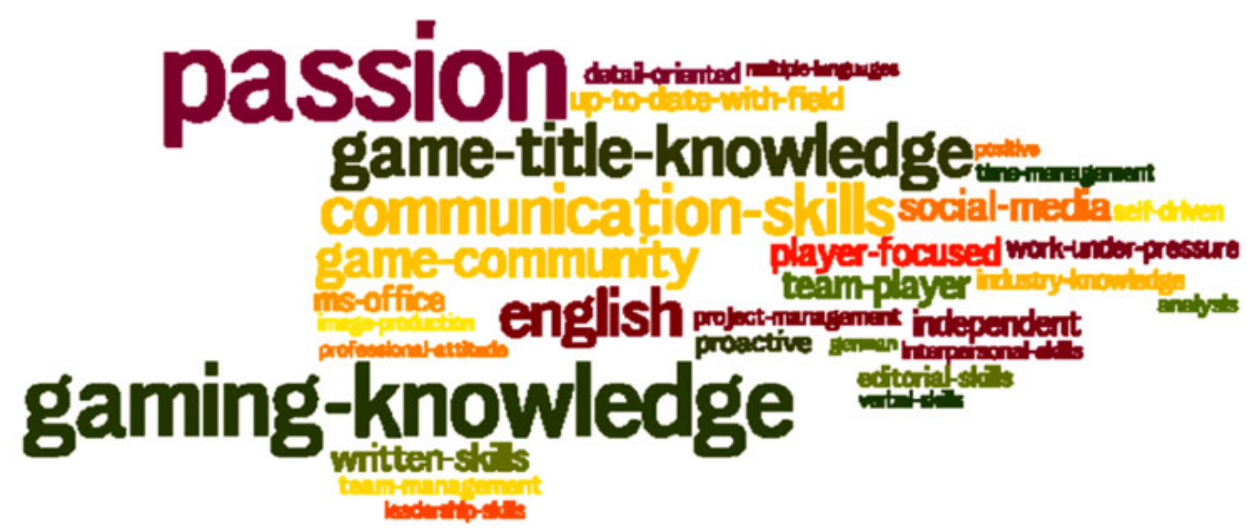

Figure 2 Tag Cloud of Frequency of All Skills

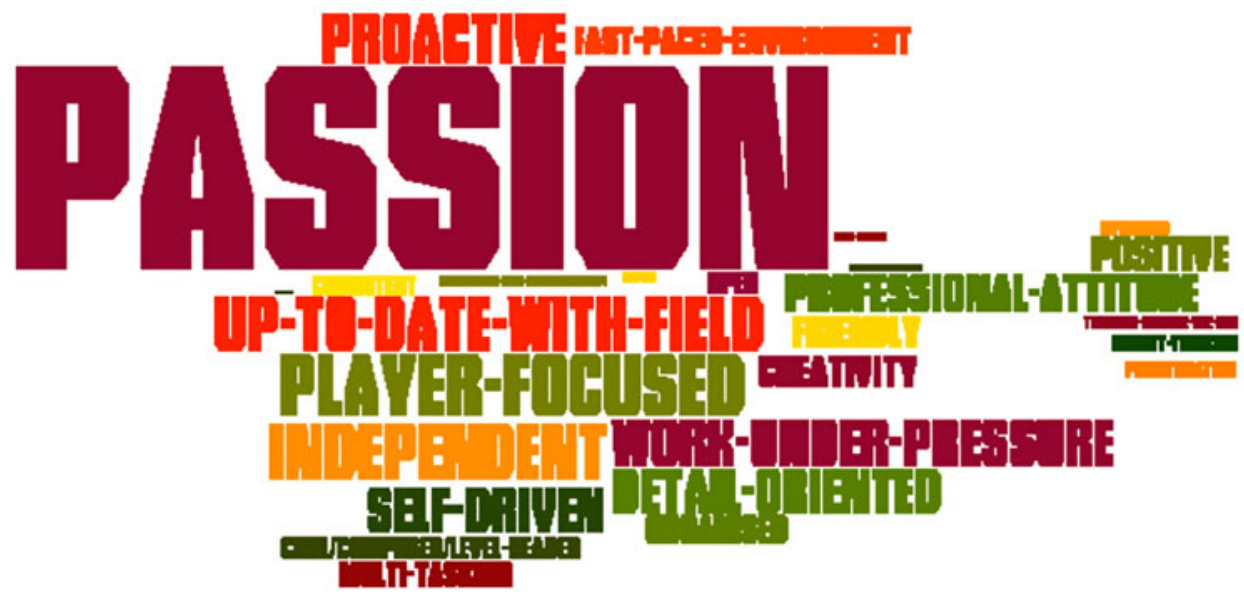

Figure 3 Tag Cloud of Frequency of 'Other Skills'-Subset of All Skills

We're looking for humble but ambitious, razor-sharp professionals who can teach us a thing or two. We promise to return the favour. Like us, you take play seriously; you're passionate about games. (Riot, Dublin, Ireland)

These findings underline the importance of gaming capital (Consalvo, 2007), and signal that these are opportunities for fans to turn their gaming capital into economic capital. It is an opportunity for those who have been engaged in "playbour" to become involved in waged labour (Kücklich, 2005). In addition, these companies are looking for employees who are passionate about the game, the company, and the player community, and who can communicate and trade on the insider and tacit knowledge that comes with their formal and informal experience. The use of "humble" in the quotation above, and "nurturing" in the quotation below, demonstrates how the language of care, modesty, and self-effacement-not qualities we usually associate with creative work-are deployed. 


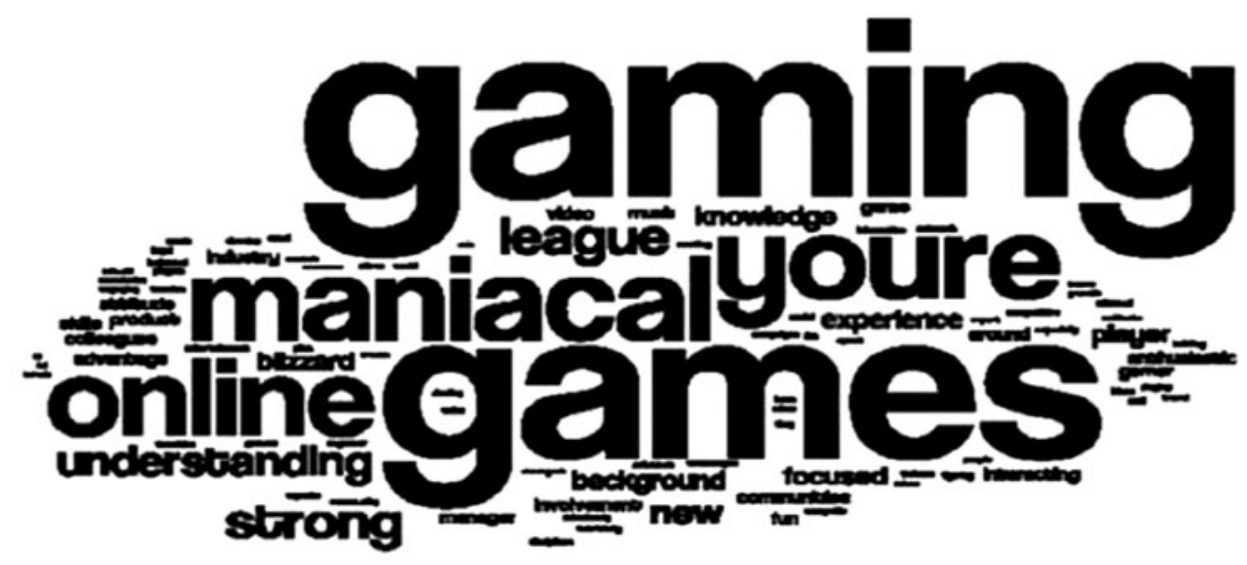

Figure 4 Tag Cloud Showing Co-occurrence of Words with the Word Passion

A community manager is someone who nurtures collective passion ... So the way you do that is not by, say, having ego issues and thinking you're some kind of rock star. The way you do that is by being the kind of guy who is going to showcase other people and who's going to help build a social atmosphere that is really cool ... You are someone who is going to create an environment that is going to make people feel good about their passion, about what they do that's linked to that passion ... So you need the right personality for this. (Int. 9, male, aged 33]

\section{The Work of Community Managers}

Blizzard Entertainment is seeking a manager passionate about the gaming industry, player communities, communication, and social media. They will oversee the design and execution of community engagement programs, manage a team focused on the player community, and lead the editorial direction of content to be published via our social media outlets, blogs, and forums. (Activision-Blizzard, California, USA)

Electronic Arts, the world's leading independent developer and publisher of interactive entertainment software is seeking a community manager to manage and execute online and social product strategies. Reporting to the Director of Global Product Marketing, the community manager may work on one, or multiple games, simultaneously. This role is embedded (and physically located) in the game team studio to improve communication and to give community more visibility into game features, content, promotions, game development status and roadmap ... The community manager is the owner of published content on Facebook fan pages, websites, forums, and other community channels (i.e. Twitter, blog, YouTube if applicable). He/she constantly monitors the community channels to communicate, to engage, excite, and trouble shoot for fans, with the ultimate goals to drive traffic, engagement, brand loyalty, and revenue for the assigned games. (Electronic Arts, Helsinki, Finland)

While passion and community are deployed in recruitment, they may also be important in terms of understanding the work of community managers. It is clear 
from the advertisements and the interviews that the role of the community manager is complex, creative, and challenging. They are sometimes co-located with development teams, as in the second advertisement, but in other cases they are offshored and remote from the development team. In some instances they are heavily involved in creating social media content, marketing promotions and outreach engagement programs, but ultimately it is clear that they are engaged in driving traffic and revenue. They must also entertain game players. Interviewees talked about developing an online persona and a writing style. Our interviewees all saw this role as creative and most felt that they were part of the games industry even though none of our interviewees were co-located with development teams. The biggest challenge faced by our interviewees was influencing product development and communicating player issues to the relevant other teams in the company. There were clearly organizational hierarchies in the larger companies and these meant that access to the core development team was often difficult.

The second biggest challenge was managing problematic player behavior and communications. Both male and female interviewees performed both mediated and face to face emotional labour (Hochschild, 1983), remaining calm and helpful despite the often emotionally charged context. They have to deal with threats of suicide, political arguments, sexism, racism, and homophobia, and know the cultural backgrounds of their players in order not to offend. Hacking and exposure of player data was another challenge and community managers had to manage the communications surrounding these issues. One male interviewee who had worked in the industry in two major multinational game companies noted that it was important "not to take things personally" or to "bring things home." One women interviewee stated that you needed to be empathetic, try to think like players, predict their actions and adjust your own accordingly.

Q: So, what do you think are the main skills a community manager needs?

A: Well, communication.

Q: Is that oral, written, what do you mean?

A: In every possible way. You need to get to the point somehow and then you have be kind of controlled, because sometimes you have, you have nice days, when the community, it's nice to you, but you have many, many, days when everybody's shouting and insulting each other, insulting you and you have to find a way to gain their trust to calm things down. It's a bit like a diplomatic job, in a way. (Int. 11, female, aged 28.)

Community managers have to maintain an apolitical, culturally nuanced subjectivity online that may, or may not, coincide with their offline identity. All interviewees raised this, but one women community manager talked about deploying particular masking techniques (i.e. in their choice of nickname, etc.). Another male interviewee told me you always have sexism and that a core challenge is making sure that the gameworld and the related social media channels are "safe places" for everybody. 


\begin{abstract}
A: ... when I was working on the Italian market at the very beginning I wasn't really saying that I was a woman, I wasn't saying anything, I said that at the end of the project.

Q: Would you use your name- or a different name?

A: Yeah, a nickname. Because at the time the community wasn't really mature, so we wanted to avoid issues with players not taking women seriously or that kind of stuff. (Int. 11, female, aged 28)
\end{abstract}

While contracted working hours were relatively normal, actual working hours were unpredictable. One interviewee talked about being the only community manager in an international start up - as a result they had on occasion slept overnight at the office. Others had to work shifts or work flexibly across time zones including North America and Asia. Interviewees talked about how stressful the job was and the pressure to answer "tickets" as quickly as possible. Another noted that you needed to really like the job and watch out for "burn out." The larger context of this is that these positions are relatively poorly paid, and upstream decisions on revenue flows, or new projects, could lead to games being closed down, restructuring of teams and jobs disappearing at short notice.

None of our interviewees were members of a representative organization, although some were part of closed "Linked In" groups or turned to games industry websites to connect with the wider industry. Apart from their direct team, they had largely individualized roles and most had "portfolio" careers, having worked in a number of companies in different countries and on many different game projects. At the same time many told me that they would use their friendship and informal social networks to search for work. The Gamasutra (2014) survey also identified the importance of referrals for seeking employment. Companies are increasingly recruiting new community managers from within the player community, reinforcing the finding of our content analysis that formal qualifications are not a requirement.

Overall, the impression we get of community management work is that it is relatively poorly paid, or certainly on the lower end of the salary scale in the games industry. While more women are employed in this area than in other areas of the industry, all workers still face issues associated with precariousness-long working hours complicated by working in production networks that stretch across time zones, crunch periods, projects, and jobs disappearing with relatively little notice, informal hiring and recruitment processes, and a sometimes hostile workplace culture. The relevant workplace culture here is the virtual workplace of the gameworld and the associated social media channels. For the workers trying to keep calm and trying to keep the game players calm is their core challenge. For the more senior workers, monitoring and managing projects, games, and teams are the core challenge. Another key task is the reporting of data and trends. These management and reporting skills are rarely mentioned in the job advertisements and seem undervalued and underpaid. In general these roles are rather loosely defined and interviewees noted that performance management was ill-defined as a result. 


\section{Conclusion}

Our findings suggest that community managers sit between developers and game players in the production network but are an important element in maintaining capital flows. They are extensive users of social and digital media but they also organize offline events including face to face conventions. They telework, in that their day job is mediated via computer and the internet, but most are co-located with their fellow community managers in teams. They do not play games as part of their job but they are expected to be avid players/gamers and knowledgeable of the games that they support. With the exception of a few internship positions, most are paid positions although their salaries are undisclosed. They produce a lot of content for social media but they do not produce the core product at the heart of the service. They are mobile and multilingual, often doing informal translation work.

Community management relies heavily on native language cultural knowledge, soft skills, experience, and gaming knowledge. Indeed one interviewee stated that "soft skills were $80 \%$ of the job" (Int. 9, male, aged 33). Workers must both take care of their own emotions as workers and of the emotional state of the game playing community. Online game players are encouraged to feel like they belong to a community of interest, one in which their gaming knowledge and commitment is rewarded in direct and indirect ways. Community managers "perform" diplomatic apolitical subjectivities to mediate a range of problematic user behaviors, and in some cases need to mask aspects of their identity depending on the type of game world/community they are working with. As such they have much in common with Hochschild's (1983) air hostesses and debt collectors, and reality television's producers (Hesmondhalgh \& Baker, 2008). In this context, passion, community, and online social relationships are employed directly in both the recruitment and the logics of cultural production.

A key concern for us must be what are the implications of this type of work for worker wellbeing? These workers are clearly part of the production network but they are largely invisible. Gaming capital and knowledge is valorized, but not completely necessary to do the job. Passion has an elevated status in recruitment processes, but its deployment seems to be a very neoliberal call for (complete) emotional commitment to the company, as Couldry and Littler argued recently (2011), and a way for both employers and employees to justify working practices that might not be acceptable elsewhere (Consalvo, 2011). Further, they deploy important aspects of the self in the performance of their job and downplay or mask other aspects (i.e. gender). They may work normal hours but most of our interviewees talked about being on call and experiencing "crunch" time during game launches. Some work shifts and flexible hours mediating between different parts of the production team and markets in different time zones. They lack any professional representation and in some cases in Ireland workers were "let go" with very short notice.

The community managers that we interviewed work as part of a team and they see their work as creative, social, and fun. This is symbolic, communication, and informational work and thus falls within most definitions of the creative and/or cultural industries even if interviewees do not necessarily see the roles as a stepping- 
stone into other areas in the industry. This work challenges simplistic notions of "above" and "below the line" as a creative/craft distinction and moves us towards examining how emergent production logics are reshaping working conditions. This labour is both "enjoyed and exploited" to borrow Terranova's (2004) phrase, since the workers both submit to and sometimes challenge the corporate cultures in which they work. At the same time their creativity, translation, reporting, and management skills are undervalued while flexibility and instability are common. While this is an ongoing project, we hope that it will contribute to opening up a new avenue for research and challenging the technological utopianism that we see in some media and policy research. In our opinion this is a new form of emotional labour where recruitment, organizational hierarchies, and in-game cultures appear to be reproducing very familiar and problematic working practices.

\section{Acknowledgements}

The authors would like to thank Katarina Vesikko for her research assistance, their interviewees for their time, and the input of two anonymous referees.

\section{Note}

[1] The UK survey has different occupational categories from the Gamasutra survey. It found that median game development salaries had dropped from the previous year, identified a male versus women salary gap, and excluded salaries below $£ 14,000$ and over $£ 100,000$ in their analysis.

\section{References}

Bakardjieva, M. (2003). Virtual togetherness: an everyday life perspective. Media, Culture \& Society, 25, 291-313.

Bakioglu, B. S. (2013). Negotiating governance in virtual worlds: Grief play, hacktivism, and LeakOps in Second Life $\hat{A}^{\bullet}$. New Review of Hypermedia and Multimedia, 18, 237-259.

Banks, M. (2007). The politics of cultural work. New York, NY: Palgrave Macmillan.

Banks, M. J. (2009). Gender below-the-line. Defining feminist production studies. In V. Mayer, M. Banks, \& J. Caldwell (Eds.), Production studies. Cultural studies of media industries (pp. 8798). New York, NY: Routledge.

Bird, S. (2006). NLTK: The natural language toolkit. Paper presented at the COLING/ACL on Interactive Presentation Sessions, Sydney, Australia.

Bolin, G. (2011). Value and the media. Cultural production and consumption in digital markets. Farnham: Ashgate.

Caldwell, J.T. (2008). Production culture: Industrial reflexivity and critical practice in film and television. Durham, NC: Duke University Press.

Caraway, B. (2011). Audience labor in the new media environment: A Marxian revisiting of the audience commodity. Media, Culture \& Society, 33, 693-708.

Consalvo, M. (2007). Cheating: Gaining advantage in videogames. Cambridge, MA: MIT Press.

Consalvo, M. (2011). Crunched by passion. Women game developers and workplace challenges. In Y.B. Kafai, C. Heeter, J. Denner, \& J.Y. Sun (Eds.), Beyond Barbie and Mortal Kombat. New perspectives on gender and gaming (pp. 177-190). Cambridge, MA: MIT Press.

Couldry, N., \& Littler, J. (2011). Work, power and performance: Analysing the 'reality' game of The Apprentice. Cultural Sociology, 5, 263-279. 
Deuze, M., Bowen, M.C., \& Allen, C. (2007). The professional identity of gameworkers. Convergence, 13, 335-353.

Dring, C. (2015, January 23). How much are you worth? Find out with the results of MCV's 2015 salary survey. $M C V$. Retrieved from http://www.mcvuk.com/news/read/how-much-are-youworth-find-out-with-the-results-of-mcv-s-2015-salary-survey/0144271

Dyer-Witheford, N., \& De Peuter, G. (2009). Games of empire: Global capitalism and video games. St Paul: University of Minnesota Press.

Gamasutra. (2014). Transitions. Salary survey. Retrieved from http://www.gamasutra.com/view/ news/221533/Game_Developer_Salary_Survey_2014_The_results_are_in.php

Gill, R., \& Pratt, A. (2008). In the social factory?: Immaterial Labour, precariousness and cultural work. Theory, Culture, Society, 25(7-8), 1-30.

Hesmondhalgh, D., \& Baker, S. (2008). Creative work and emotional labour in the television industry. Theory Culture Society, 25(7-8), 97-118.

Hesmondhalgh, D., \& Baker, S. (2011). Creative labour. Media work in three cultural industries. Abingdon: Routledge.

Hochschild, A.R. (1983). The managed heart: Commercialisation of human feeling. Berkeley: University of California Press.

Humphreys, S. (2008). Ruling the virtual world. Governance in massively multiplayer online games. European Journal of Cultural Studies, 11, 149-171.

Huws, U. (2012). Action IS1202 fact sheet. Retrieved from http://www.cost.eu/COST_Actions/isch/ Actions/IS1202

Kerr, A. (2011). The culture of gamework. In M. Deuze (Ed.), Managing media work (pp. 225236). Thousand Oaks, CA: Sage.

Kerr, A., \& Cawley, A. (2012). The spatialisation of the digital games industry: Lessons from Ireland. International Journal of Cultural Policy, 18, 398-418.

Kerr, A., De Paoli, S., \& Keatinge, M. (2014). Surveillant assemblages of governance in massively multiplayer online games: A comparative analysis. Surveillance \& Society, 12(3), 320-336.

Kücklich, J. (2005). Precarious playbour: Modders and the digital games industry. Fibreculture, (5). http://journal.fibreculture.org/issue5/kucklich.html

Lacroix, J.-G., \& Tremblay, G. (1997). The institutionalization of cultural commodification: Logics and strategies. Current Sociology, 45(4), 39-69.

Livingstone, I., \& Hope, A. (2011). Next gen. Transforming the UK into the world's leading talent hub for the video games and visual effects industries. London: NESTA.

McRobbie, A. (2010). Reflections on feminism, immaterial labour and the post-Fordist regime. New Formations, 70(1), 60-77.

Miège, B. (1989). The capitalisation of cultural production. New York, NY: International General.

Miège, B. (2011). Principal ongoing mutations of cultural and informational industries. In D. Winseck \& D. Yong Jin (Eds.), The political economies of media (pp. 51-65). London: Bloomsbury.

Neff, G. (2012). Venture labor: Work and the burden of risk in innovative industries. Cambridge: MA: MIT Press.

O’Brien, A. (2014). Producing television and reproducing gender. Television \& New Media, 16(3), 259-274.

Scholz, T. (2013). Digital labor:Tthe internet as playground and factory. New York, NY: Routledge.

Skillset. (2010). Computer games sector - labour market intelligence digest. London: Skillset.

Steinkuehler, C.A., \& Williams, D. (2006). Where everybody knows your (screen) name: Online games as third places. Journal of Computer-Mediated Communication, 11, 885-909.

Terranova, T. (2004). Network culture: Politics for the information age. London: Pluto Press.

Whitson, J. (2010). Rule making and rule breaking: Game Development and the governance of emergent behaviour. Fibreculture, 16. 